\title{
A Numerical Approach for Sound Quality of Vehicle Doors
}

\author{
Erkut Yalçın, Halil Bilal and Ayhan Yağcı \\ TOFAŞ Türk Otomobil Fabrikası A.Ş., Osmangazi 16369, Bursa, Turkey. \\ Haluk Erol \\ Istanbul Technical University, Mechanical Engineering Faculty, Gümüşsuyu, 34439, Istanbul, Turkey.
}

(Received 4 January 2018; accepted 6 June 2018)

\begin{abstract}
A Vibro-Acoustic Finite Element Method (FEM) model capable of calculating the transient sound pressure generated by the door slam of a vehicle was developed in this study. A design sensitivity analysis (DSA) was performed for investigating the effects of major design variables on the related sound quality metrics. The methodology was developed using a sedan-car and its FEM model. This paper shows that a Computer Aided Engineering (CAE) model can be used as a rather powerful tool for giving design change decisions for the door components from sound quality point of view during vehicle body development according to psychoacoustic parameters.
\end{abstract}

\section{INTRODUCTION}

In the automotive market, technology is currently being developed for use in supplying the customers not only with the standard safety and design requirements but also for more comfort and quality. Better vibration and noise performance of the vehicle also improves customer perception of the quality of the vehicle. Hence, the subjective evaluations of customers are being considered as a leading indicator for some noise and vibration studies within the research and development departments of automobile companies. One of the most important performances that can improve customer perception about the vehicle quality is the door slam noise. It is known that a tough and brief sound of door slamming creates a perception that the car is of good quality. This knowledge is the main reason why the Noise-Vibration-Harshness (NVH) teams of the research and development departments of most global automotive companies are focusing on studies to improve the impression that the door slam sound creates on customers.

The answer of the question why the door slam noise is important is originating from what it creates in the customers' minds. The typical car customers who would like to buy a car gives considerably high amount of importance to the door slam sound thinking that this sound is giving an idea about the quality of the vehicle. They typically slam the door from the outside and listen and evaluate the sound from there. When they sit on the seats and close the doors, they are interested in some functional buttons on the instrument panel and/or give special attention to the comfort of the seat, general view of the instrument panel etc. That means that they investigate the door slam from the outside, at exactly the point that they close the door after getting out of the car. On the other hand, the sound heard inside the cabin is absorbed quickly by the absorber materials covered all around the interior face of the cabin. This makes the door slam sound heard from the inside of the vehicle less remarkable. That's why the sound quality was investigated in detail from the outside, at the point of ear of an average-height customer in this study.

Outputs of the studies performed regarding the sound quality of the finished products are various. ${ }^{1-4}$ Some of them are concentrating on specifically on door slam. ${ }^{1,2}$ Additionally, the objective measurements of some psychoacoustics parameters and subjective jury evaluations were correlated in some of those studies. ${ }^{1,2}$ The impact of loudness for improving customer perception was found to be decreased from those studies. In more advanced studies, a general "impulsive sound figure" is available as a result of comprehensive studies performed, and the general rules on this figure to obtain a desired sound are stated. One of the stated rules of this study is that highfrequency sound content should be minimized, and a lower value of sharpness is desired. ${ }^{5}$ Some studies have also investigated the sole effects of different designs on sound quality. ${ }^{1}$

Creating a CAE methodology capable of leading vehicle door design studies during the early phases of product development would enable the studies in this field to be run faster, more effectively and less costly. The studies of developing a CAE methodology for the sound quality of the vehicle designs are concentrated mostly on the interior noise in vehicles. ${ }^{6,7}$ However, most of them are not concentrated specifically on door slam sound quality. The most conspicuous CAE methodology available in the literature for predicting the transient door slam noise and evaluating the sound quality is one using a twostep FEM + Boundary Element Method (BEM) analysis in sequence. ${ }^{6}$ In this study, input forces to the system are measured before the analysis and therefore it requires a physical vehicle. From that point of view, it doesn't seem possible to apply it within early steps of product development in which there is not any physical vehicle yet. On the other hand, the study presented in this paper reveals a new vibro-acoustic door slam methodology constituted purely by FEM in one unique solution instead of two. The structural side of a door slam event is performed with an explicit non-linear solution and coupled to an acoustic FEM. Transient sound pressure output from CAE analysis was validated with experimental result. At the end, some design changes were applied on the validated model and a DSA was conducted to investigate the changes of the sound quality metrics.

The first innovative point that this study reveals is that there is no need for a physical vehicle to make an early assessment of sound quality as long as you have a satisfactorily validated FEM model because the applied forces in the system purely depend on the characteristics of seals, bumpers and the latch 


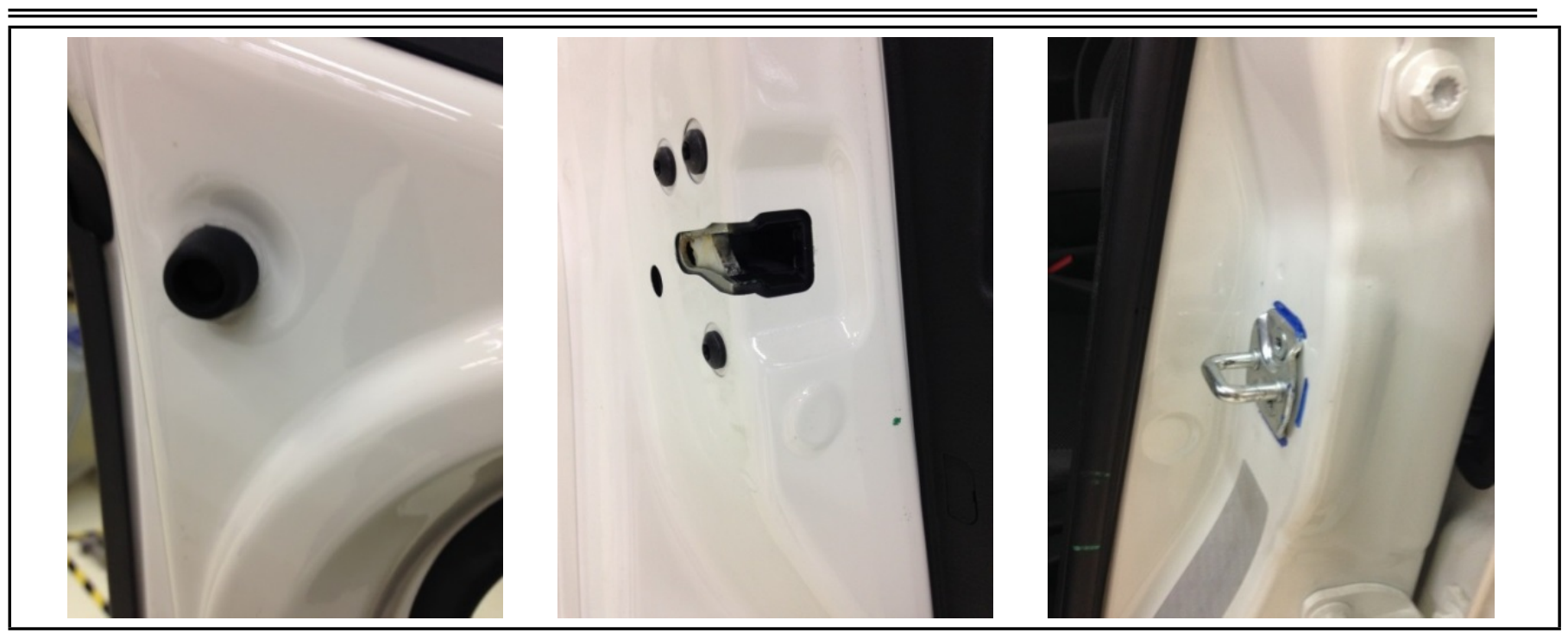

Figure 1. Elastic bumper, latch, and latch striker.

and they don't need to be on the vehicle. Having their forcedisplacement characteristics are adequate to be applied in numerical model. Secondly, the analysis is performed under one unique solution with only FEM instead of using two adjacently applied methods.

From those points of views, the numerical methodology developed in this study is eliminating the lack of existing approach. It is applicable in early steps of door design to direct the studies according not only to some common performances like durability, strength and crash but also for sound quality aspects.

\section{THEORETICAL BACKGROUND}

Door slam noise has been classified as a structure-borne noise event. The mechanism can be divided into several steps. In the first step, an initial velocity is applied to the door, and closing the door with this velocity induces some forces on the body by means of several components in contact with it such as elastic bumpers, the seal around the body and the latch mechanism (Fig. 1). The same forces also act on the door as reactions. As a result, some amount of energy is injected into both the body and the door. In the second step, the parts receiving the door slam energy transfer it to other mechanically connected parts and all of those structural components begin to vibrate with this excitation regardless of their direct connection to the door.

Lastly, all vibrating parts in touch with the acoustic cavities (interior or exterior) radiate some sound into the air inside. However, the most of energy is being radiated still from the door itself. This mechanism gives the idea that the vibrations comprising the door slam noise are distributed in a wide range of frequencies. As the nature of the aforementioned mechanism requires, more than one force acts on the system.

Seal forces $\left(F_{\text {seal }}\right)$, which are created when the seals around the door are compressed, apply on the parts it contacts. Elastic bumpers are also important contributors to the door slam noise. They behave like a spring, and some amount of force is induced on the body by them. This force can mathematically be defined as the product of the stiffness of the bumper $\left(k_{\text {bumper }}\right)$ and the elastic deformation to which they have been exposed ( $\left.x_{\text {bumper }}\right)$ :

$$
F_{\text {bumper }}=k_{\text {bumper }} \times x_{\text {bumper }} .
$$

The latch force $\left(F_{\text {latch }}\right)$ is rather hard to measure but essential to be included in the system. It can be analytically expressed as the product of the stiffness of the latch spring and the displacement of the latch fork: ${ }^{8}$

$$
F_{\text {latch }}=k_{\text {spring }} \times x_{\text {fork }} .
$$

The injected power to the system by means of point forces such as elastic bumpers and latch forces can be defined as: ${ }^{9}$

$$
W_{i n}=\left|\frac{1}{2} \hat{F}_{0}^{2}\right| \operatorname{Re}\left\{\frac{1}{Z_{F \infty}}\right\} .
$$

Here, $W_{i n}$ is defined as the injected power to the system by means of a point force. $\hat{F}_{0}$ and $G_{F F}$ are the maximum amplitude and the spectral density of the exciting point force. $Z_{F \infty}$ is the point force impedance and can be defined as: ${ }^{9}$

$$
Z_{F \infty}=\frac{F_{0}}{v_{0}} .
$$

Here, $v_{0}$ is the velocity of the point on which the excitation force is applied, and $F_{0}$ is the excitation force itself.

Structures that gain a velocity in this manner radiate the sound into the acoustic environment. The sound radiation ability of the parts is highly dependent on a parameter called radiation efficiency $\left(\sigma_{\text {rad }}\right)$. Radiation efficiency (or radiation ratio) is defined as the sound power radiated by the structure into half space divided by the sound power radiated by a large piston with the same surface area and vibrating with the same root mean square velocity as the structure and is a mainly used parameter in studies investigating structure-borne sound. ${ }^{10,11}$ It is known that the parts that radiate sound most are the thin wide panels such as the outer door panel. The waves in those panels that create sound are mostly bending waves.

There are also some damping forces, which dissipate the energy injected into the body and the door. One of them is the damping force of the seals. The Abaqus Explicit Finite Element Solver models the damping force at the surfaces that are in contact by means of the seals (in our case the door and body surfaces) with the below equation:

$$
f_{v d}=C_{f} A_{f} v_{r e l}^{e l} .
$$


In this equation, $C_{f}$ is the damping coefficient and defined as the pressure on the contact surface per unit of relative velocity between opposite surfaces in contact $\left(v_{r e l}^{e l}\right) . A_{f}$ is the contact surface area.

Again, there are several types of material damping techniques. Abaqus Explicit uses a Rayleigh type damping which is defined as:

$$
\xi_{i}=\frac{\alpha_{R}}{2 \omega_{i}}+\frac{\beta_{R} \omega_{i}}{2}
$$

Here, $\xi_{i}$ is the damping ratio for the mode $i$. In addition, $\omega_{i}$ is the natural frequency of the mode $i, \alpha_{R}$ is the massproportional damping coefficient and $\beta_{R}$ is the stiffness proportional damping coefficient. It can be seen clearly that Rayleigh type damping here is dependent on natural frequencies and therefore not constant.

As stated before, when the door is slammed, the excited part is not just the car body but also the interior acoustic cavity. The excitation of the structural panels of the car gives rise to the deformation of the acoustic cavity. The elastic structure responds to those deformations in the cavity, and in this manner a coupling between structural displacements and pressure changes in the acoustic cavity occurs. ${ }^{12}$ A high-amplitude and low-frequency noise called "Booming Noise" occurs in the regions where this type of coupling is high. For this reason, any vibro-acoustic method investigating interior noise must consider structural-acoustic coupling. ${ }^{12-14}$ Interior trim parts affect the cavity modes and sound pressure level created inside because they both constitute geometrical boundaries of the cavity and have sound absorbing materials affecting the impedance boundary conditions for the cavity. ${ }^{15,16}$

Actually visco-elastic bumpers have also damping properties. However, for this specific study, it was less important numerically when compared to dissipation forces resulting from the damping of materials (applied to all panels) and seals (applied onto all surface the seal is applied). For this reason, dissipation of elastic bumpers wasn't taken into consideration in order not to make our model more complex to be solved.

The door slam simulation presented in this study comprises a coupled finite element solution of structural and acoustic parts. The structural part is a direct integration dynamicexplicit part. The non-linear equation of motion at the $\mathrm{n}^{\text {th }}$ time interval is: ${ }^{17}$

$$
[\tilde{M}]\{\ddot{u}\}_{n}+[C]\{\dot{u}\}_{n}+[K]\{u\}_{n}=\left\{R^{e}\right\}_{n} .
$$

An explicit algorithm uses a difference rule suitable to the generalized form below and includes the statements belonging to the previous time steps on the right side only:

$$
\{u\}_{n+1}=f\left(\{u\}_{n},\{\dot{u}\}_{n},\{\ddot{u}\}_{n},\{u\}_{n-1}, \ldots\right) .
$$

$\left\{R^{e}\right\}_{n},\{\ddot{u}\}_{n},\{\dot{u}\}_{n}$ and $\{u\}_{n}$ are the exterior force, acceleration, velocity and displacement vectors at the $\mathrm{n}^{\text {th }}$ step, respectively.

At the end of the door slam, small sound pressure changes occur in the acoustic cavity with the help of the structure which has a specific amount of movement. The equilibrium equation for the small movements of the compressible and adiabatic fluid is defined as follows:

$$
\frac{\partial p}{\partial x}+\gamma_{d}\left(x, \theta_{i}\right) \dot{u}^{f}+\rho_{f}\left(x, \theta_{i}\right) \ddot{u}^{f}=0 .
$$

In this equation $p, x, \rho_{f}$ and $\gamma_{d}$ are the excess pressure above the static pressure, the spatial position of the fluid particle, the
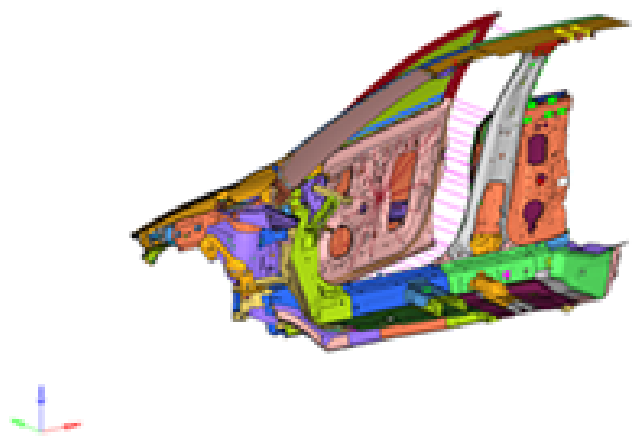

Figure 2. Cut car model.

density of the fluid and the volumetric drag, respectively. $\theta_{i}$ represents $i$ number of independent variables such temperature and humidity in the air. Lastly, $\dot{u}^{f}$ and $\ddot{u}^{f}$ are the velocity and the acceleration of the fluid particle, respectively.

Sound quality parameters are criteria enabling the subjective impression created by the sound to be evaluated. Although there are more parameters, most conventional ones are seemed as loudness and sharpness. ${ }^{18}$ In this study, the most important two (loudness and sharpness) were evaluated. Loudness is defined as the perceptual measure of the energy content of sound on the ear. The second parameter investigated is sharpness, which is a sensation value related to the spectral characteristics of the sound and caused by the high-frequency content of the sound.

\section{NUMERICAL STUDIES}

The FEM door slam model was constituted within Hypermesh pre-processor as two main parts: structural and acoustic. The structural part was one cut from a complete vehicle body FEM model and includes the door being slammed and some surrounding parts (Fig. 2). The door was 15 degrees open at the beginning. The acoustic part includes an exterior cavity representing the outside of the vehicle. This exterior cavity was created as a quarter-sphere and with hexagonal acoustical elements at the beginning and then morphed such that its outermost surfaces of contact with the door would be aligned with the shape of open door. Finally, these outermost faces of outermost elements of acoustic cavity and faces of 2-dimensional elements looking to the cavity side were tied with proper contact definitions in order to allow the acoustic elements to deform during the door slam. This deformation lets the acoustic pressure to be calculated at acoustic element nodes. The three main parts of the door are the exterior door panel, interior door panel and door glass. There are some sub parts working as strengthening elements within the door like crossbeam and latch support sheet. The other fundamental parts are the seam welds between the outer and inner panels and spot welds between the sub-parts and the main panels. The latest major part to be investigated is the door seals. The seals around the body and the door were modelled as a surface interaction in which the force - displacement curve and the damping characteristic of the seal was defined. Elastic bumpers (or elastic stoppers) and the lock mechanism were modelled as connector elements of the Abaqus Explicit solver. The length of those elements decreases when the door is being closed; when they have neg- 


\begin{tabular}{|c|c|c|c|}
\hline $\begin{array}{l}\text { Element } \\
\text { Dimensions }\end{array}$ & Element Type & $\begin{array}{l}\text { Element Name } \\
\text { (Abaqus Explicit) }\end{array}$ & $\begin{array}{l}\text { Element } \\
\text { Node } \\
\text { Numbers }\end{array}$ \\
\hline $3 \mathrm{D}$ & $\begin{array}{l}\text { Hexagonal (Solid) } \\
\text { Pentagonal (Solid) } \\
\text { Hexagonal (Acoustic) } \\
\text { Pentagonal (Acoustic) } \\
\text { Tetragonal (Acoustic) }\end{array}$ & $\begin{array}{l}\text { C3D8 } \\
\text { C3D8R } \\
\text { C3D6 } \\
\text { AC3D8R } \\
\text { AC3D6 } \\
\text { AC3D4 }\end{array}$ & $\begin{array}{l}8 \\
6 \\
8 \\
6 \\
4\end{array}$ \\
\hline $2 \mathrm{D}$ & $\begin{array}{l}\text { Quad } \\
\text { Quad } \\
\text { Quad } \\
\text { Tria } \\
\text { Tria } \\
\text { Tria }\end{array}$ & $\begin{array}{l}\text { S4 } \\
\text { S4R } \\
\text { R3D4 } \\
\text { S3 } \\
\text { S3R } \\
\text { R3D3 }\end{array}$ & $\begin{array}{l}4 \\
4 \\
4 \\
3 \\
3 \\
3\end{array}$ \\
\hline $1 \mathrm{D}$ & $\begin{array}{l}\text { Rigid } \\
\text { Rigid } \\
\text { RBE 3 } \\
\text { Connector }\end{array}$ & $\begin{array}{l}\text { BEAM } \\
\text { COUP_KIN } \\
\text { COUP_DIS } \\
\text { CONN3D2 }\end{array}$ & $\begin{array}{l}2 \\
2 \\
2 \\
2\end{array}$ \\
\hline Dimensionless & Point & MASS & 1 \\
\hline
\end{tabular}

ative length, their restoring forces which are defined according to the characteristics of elastic stoppers and the lock apply to the door in the opposite way. All the sheet metal parts were constituted by 2D shell elements in the model. The door side latch was also modelled with 2D elements, but they are rigid as a difference. Elements of adhesives, hinges and acoustic cavity are 3D. Door inner side trim parts (like inner trim panel and loudspeaker embedded inside it) and some outer side parts like outer side glass and door handle were modelled as zerodimensional mass elements. The details for elements and their special names for Abaqus-Explicit were presented in Tab. 1. By this way, the complete model was created (Fig. 3).

The outer panel face and the outer face of the door glass were in contact with the outer cavity elements beside them. In this manner, the outermost acoustical elements of the cavity deformed by the movement of the door and the displacements of the acoustic elements enable the creation of acoustic pressure at their nodes. The numerical model was designed to capture $500 \mathrm{~Hz}$ frequency as the upper band limit which was seen high enough for investigating structure-borne sound.

An initial velocity was applied to the door. During the closing of the door, the forces created by the door seal, elastic bumper and the latch apply on the door according to their characteristics as indicated in Figs. 4, 5 and 6 respectively.

The pressure induced on the body by the door seal forces was created during the compression (deformation) of the seals. The term "displacement" in this curve stands for the displacement of the connector element nodes on the door side with respect to the corresponding nodes of the same elements on the body side. Under an offset amount of distance, which represents the un-deformed length of the seal, the pressure is created indicating that the seal started to be compressed (Fig. 4).

In Fig. 5, the behavior is exactly same of that with the seals. The pressure induced on the body by the bumper forces was created during the compression (deformation) of the bumpers. The term "displacement" in this curve stands for the displacement of the connector element nodes on the door side with respect to the corresponding nodes of the same elements on the body side. Under an offset amount of distance, which represents the un-deformed length of the bumper, the pressure is created indicating that the bumper started to be compressed.

The restoring force induced on the body was created by the latch after some specific amount of interference of the node of the connector element of the door side with the one of the body

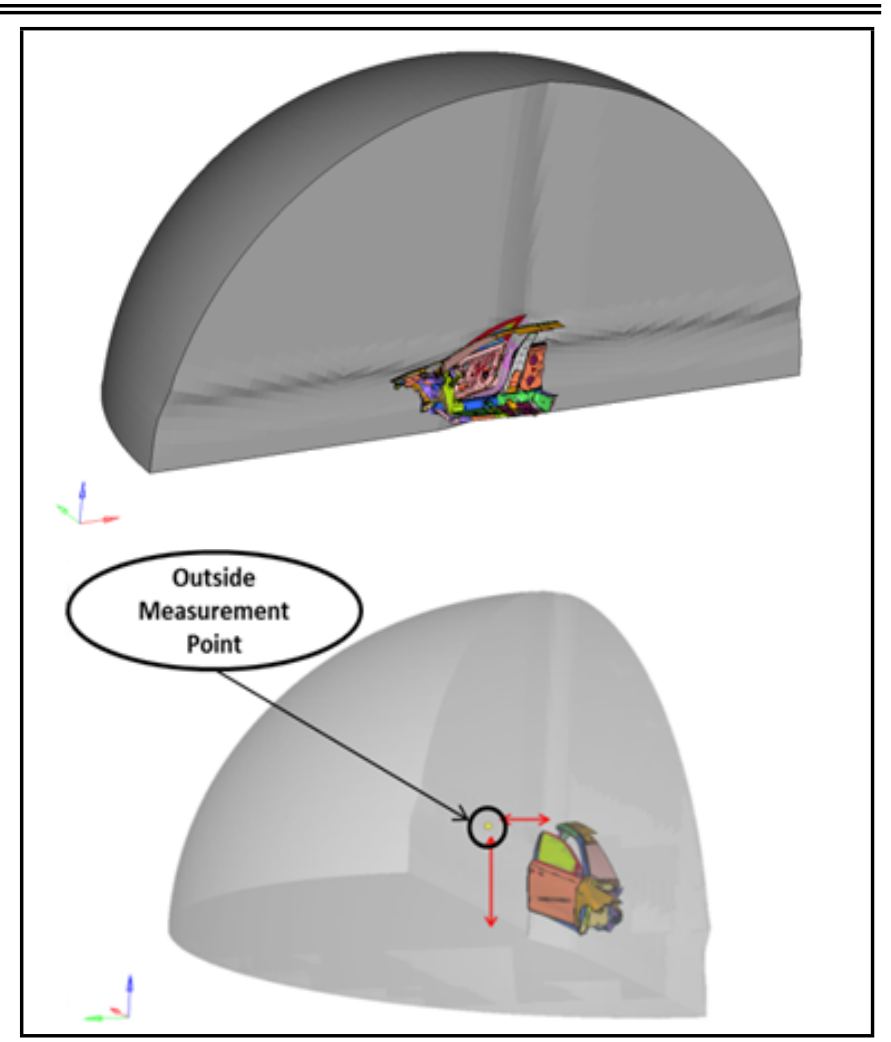

Figure 3. Complete model overview (above) and sound pressure measurement point (below).

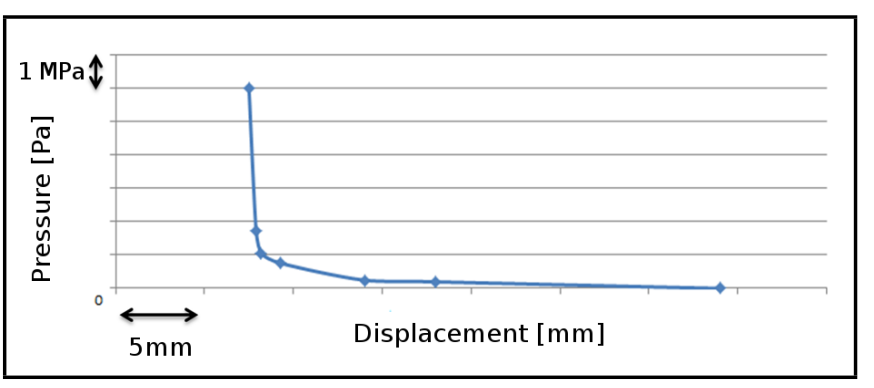

Figure 4. Pressure - displacement curve for door seal.

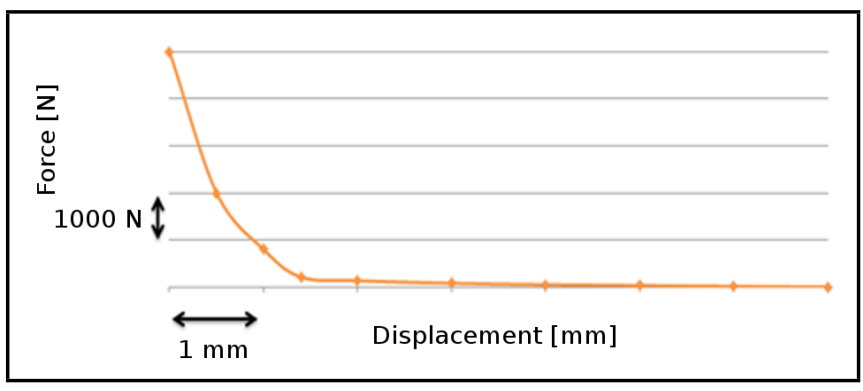

Figure 5. Force - displacement curve for elastic bumpers on the door.

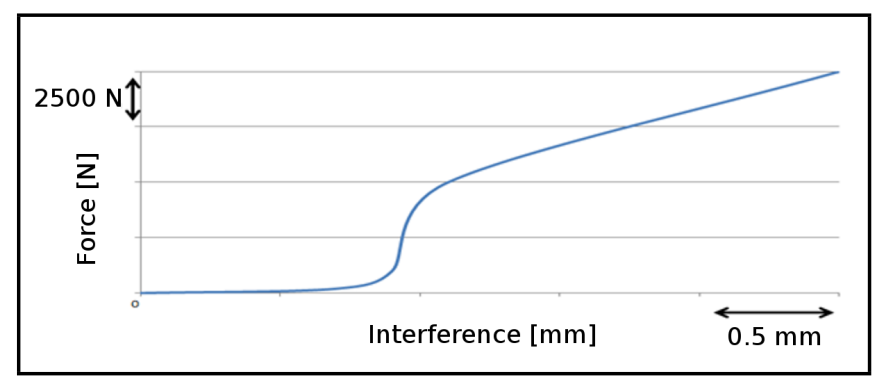

Figure 6. Latch force - interference curve. 


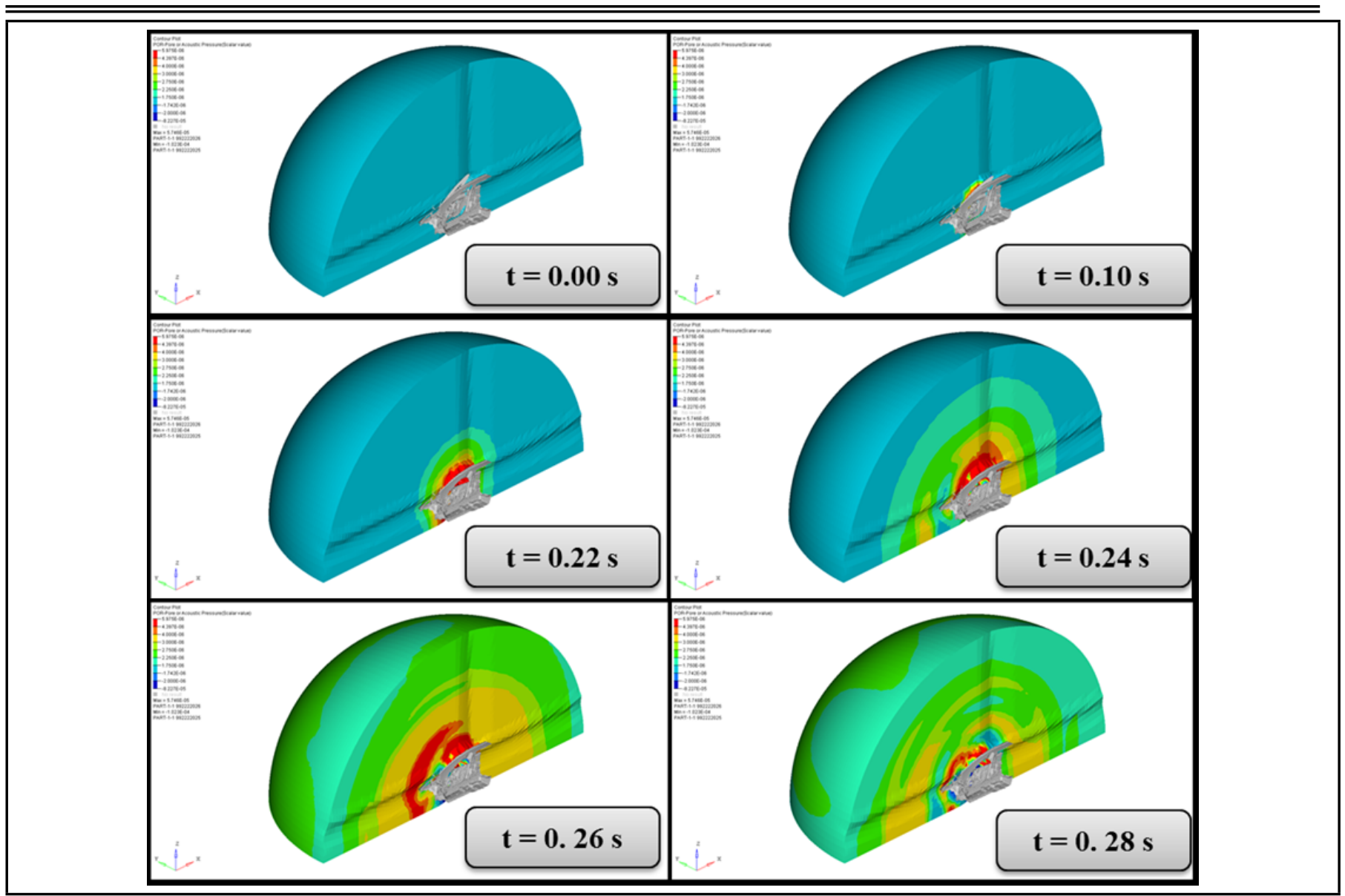

Figure 7. Representation of sound pressure inside the outer cavity for different moments.

side. This amount is directly related to the spring characteristic of the latch mechanism (Fig. 6).

Beside it, the cavity elements that were in contact with the door began to deform with the door movement beginning from the first moment that the initial velocity was given. Because of this movement of the acoustical element nodes, the sound pressure there was calculated. The only discarded phenomenon at the end remained as the air flow, which is something beyond the capability of the calculation method, but its effect was expected to be little since we're dealing with exterior noise.

The measurement point in the virtual model is shown in Fig. 3. It is at the same position with the head used in experimental test. The position is one meter away from the latch point of the door and has a height of 1.6 meters from the ground. A non-reflecting boundary condition was applied on the outermost element surfaces of the cavity again to maintain the test conditions which were being held in a semi-anechoic room. The number of elements in the model was roughly close to 600,000 . The transient sound pressure distribution inside the cavity with a colour map in different moments as a result of door slam can be seen in Fig. 7. Related curve is presented in Fig. 9 with experimental results.

\section{EXPERIMENTAL STUDIES VERIFICATION}

To validate the numerical results, a door slam test was performed in a semi-anechoic room with the car for which the FEM model was used for simulation (Fig. 8). During the test, all of the glasses of the doors were closed. The driver's door was selected as the door to be tested, and the door was tied

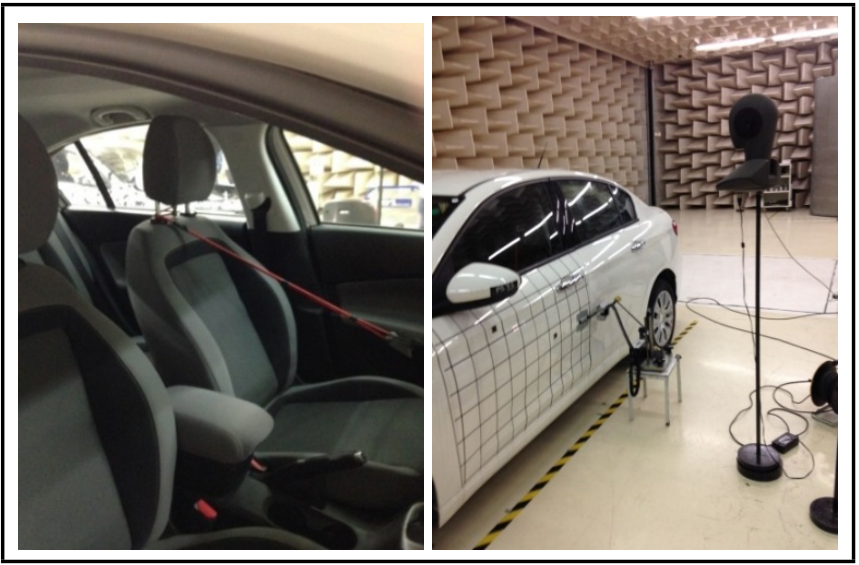

Figure 8. Set-up and measurement of door slam.

with a bungee rope from the armrest of the door to the seat headrest rods. The door was released to satisfy the same velocity at the same relative position with respect to the body as the door in the numerical model. The measurement from outside the vehicle was performed at the same point (having the same relative positions with respect to the vehicle) as that at which the sound pressure level was calculated in the virtual model. For the sound pressure measurement, a digital head with two microphones at the ear positions (HMS 3 HEAD) by HEAD ACOUSTICS was used, and the measurements were recorded by Artemis software by HEAD ACOUSTICS with a $48 \mathrm{kHz}$ sampling frequency, $104 \mathrm{~dB}$ range and 24 bits of signal processing resolution. Then, the mean of the two microphone responses were taken as the result. The head position is 1 me- 


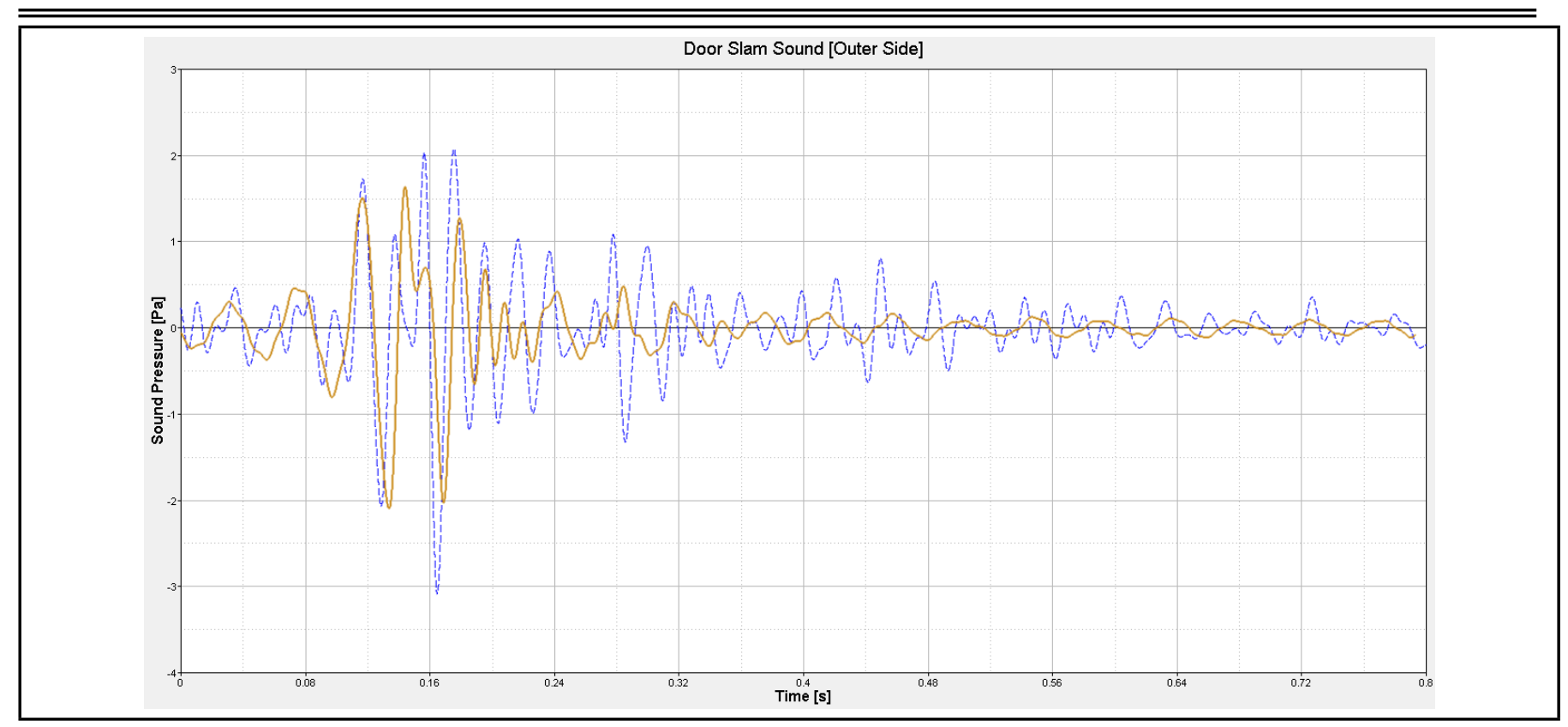

Figure 9. Comparison of door slam sound from the exterior between test and virtual analysis.

ter away from the door and had a height of 1.60 meters from the ground as declared before.

As seen from Fig. 9, the performance of FEM method for predicting transient door slam noise heard from the exterior of the vehicle was considerably satisfying from the perspective of slam time and the amplitude at that moment. However, the ongoing peaks of the simulation were higher than those of the physical test. It can be said that the model could not damp the sound sufficiently in the same manner with the physical damping mechanism. The result can be improved with more realistic damping models.

Additionally, this fact can be seen from the FFT of this experimental-FEM comparison (Fig. 10). Both experimental and FEM results were represented in 1/3th octave band. FFT results show that the frequencies within the bands with central frequencies of $25 \mathrm{~Hz}, 50 \mathrm{~Hz}$ and $100 \mathrm{~Hz}$ are matching well enabling a precise enough representation of transient results in Fig. 9.

\section{PARAMETRIC STUDIES AND SOUND QUALITY}

After validation of the numerical model, some design changes were applied (Tab. 2) and a design sensitivity analysis was performed (Tabs. 3 and 4) to understand the effects of these changes to sound quality metrics (Loudness and Sharpness). Both parameters were calculated up to $500 \mathrm{~Hz}$ frequency limit according to which the numerical model was designed to capture as the highest frequency content. Figure 11 shows some of the parts whose thicknesses were selected as the design parameters.

Thickness of outer door panel: Despite the fact that the outer door panel has a considerable amount of curvature, its highly flat surface has many bending modes. This structure allows it to be a good sound radiator; thus, it is one of the main contributors to door slam noise. Considering this, the thickness of the outer door panel was selected as a design parameter.

Thickness of inner door panel: The inner door panel plays an important role in the dynamic behavior of the door. It was suspected to be effective for the door slam sound because of its
Table 2. Design Changes for DSA.

\begin{tabular}{||l|l|l|}
\hline Case \# & Case Name & Change [\%] \\
\hline 1 & Outer Door Panel Thickness & $(+) 50$ \\
2 & Inner Door Panel Thickness & $(+) 50$ \\
3 & Door Seal Stiffness & $(+) 20$ \\
4 & Hinge Support Bracket Thickness & $(-) 20$ \\
5 & Door Latch Support Bracket Thickness & $(+) 30$ \\
6 & Door Glass Thickness & $(+) 15$ \\
7 & \multicolumn{2}{|l}{30} \\
\hline
\end{tabular}

mechanical connection to both the outer door panel and door glass which are considered to be the most important contributors to the sound pressure level. Hence, the thickness of the inner door panel was selected as the second design variable.

Stiffness of door seals: Door seals are very important parameters affecting the door slam. They behave like a spring between the door and vehicle body tuning the slam heaviness. For this reason, door seal stiffness was selected as the third design parameter.

Thickness of hinge reinforcement bracket: Hinges are important parts connecting the door to the body and are thus a vibration transmission pathway between doors and the body. They are strengthened with a reinforcement bracket inside the door, and thus the thickness of this reinforcement bracket was identified as another design parameter.

Thickness of latch reinforcement bracket: The latch of the door is one of the most important mechanisms characterizing the door slam sound. Because the latch model constituted in this study comprised basic rigid shell elements, it was not possible to determine the different latch mechanism effects on the virtual model. On the other hand, the latch reinforcement bracket, on which the latch is constrained, could be investigated. For this reason, the thickness of the latch reinforcement bracket was selected as a design parameter.

Thickness of door glass: The door glass constitutes one of the largest two panels of the door with the outer door panel. Although it is not as elastic as a steel panel, is still an important radiator. The thickness of the door glass was selected as the last design parameter.

It can be seen from the DSA results that the most effective solutions for a better door slam noise is to increase the stiff- 


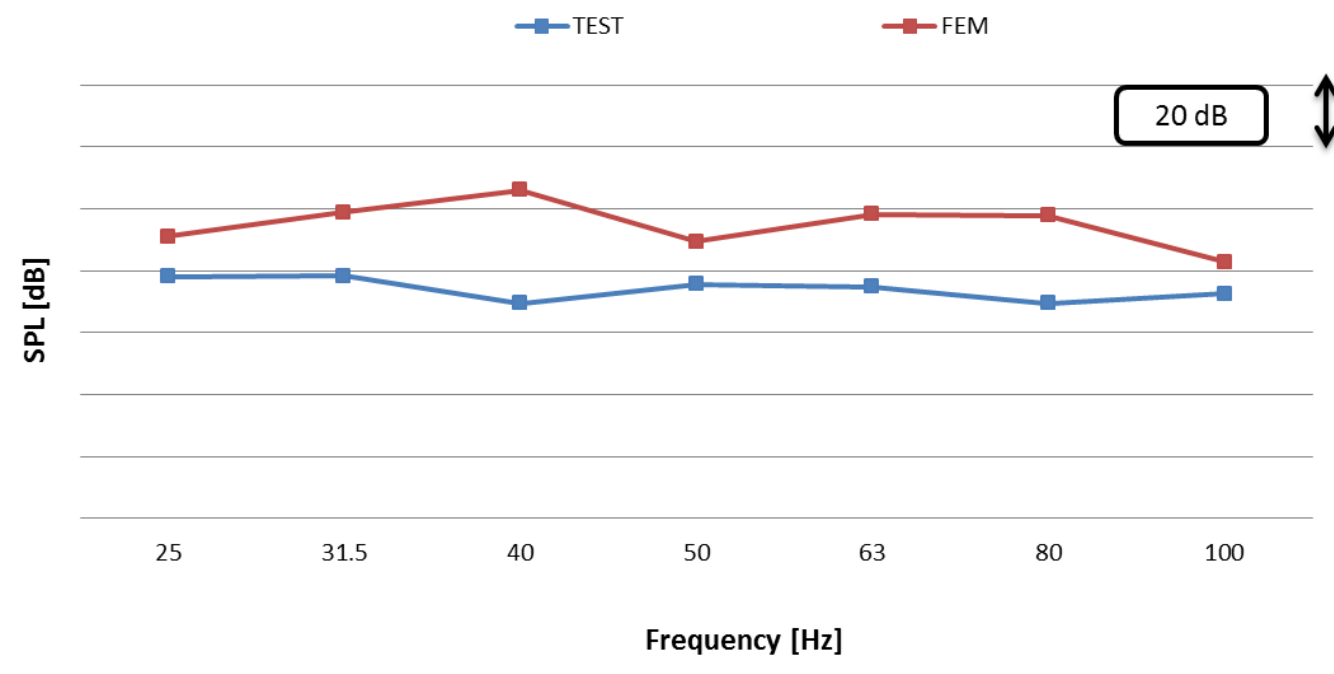

Figure 10. Comparison of the FFT of door slam sound from the exterior side (1/3th Octave Band).

Table 3. Evaluation of design change effects on Loudness.

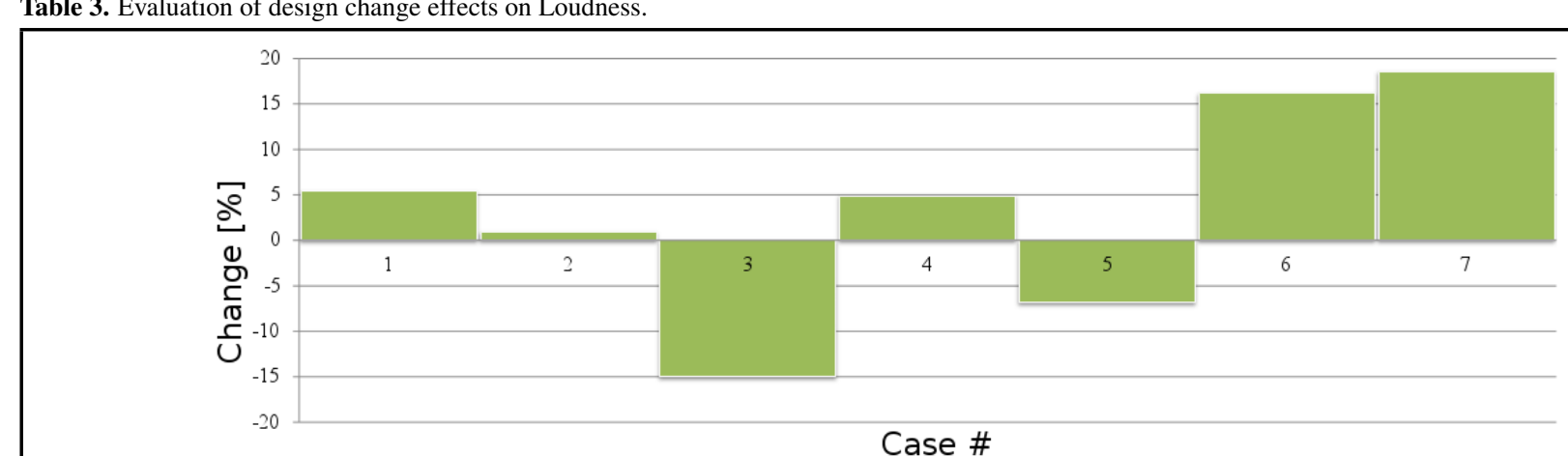

ness of the door seals and increase the hinge support bracket thickness. One point to be investigated is the different effects of increasing the inner and outer door panel thicknesses to the sound quality metrics. It can be observed from Tabs. 3 and 4 that although the effect of outer panel thickness increase affected the sound quality metrics in negative way, the same design change for the inner panel has resulted majorly in positive direction (if we ignore the very small increase in the loudness). One reason of this different behaviour is that, although the initial thickness values and increase amounts are the same for both, the inner panel is larger resulting with a mass of \% 25 higher than that of outer panel.

\section{CONCLUSIONS}

In this study, a coupled structural (non-linear) - acoustic finite element model was developed and low-frequency transient sound pressure curve for the door slam event was calculated in cavity point representing the ear location of a person slamming a door from the outside. After validation with experimental tests in time domain, some design modifications were performed, and sound quality metrics were investigated. Despite the open points to be improved, an effective CAE methodology that enables NVH engineers to direct the development process while also considering customer perception by means of comparing the analysis results of different designs was developed as the most valuable output of this study.

\section{REFERENCES}

1 Kumar, N. J., Kumar, R. P. S., and Nair, S. Experimental approach to improve the door slam noise quality in utility vehicles, Symposium on International Automotive Technology 2013, India, January 9-12, (2013). https://dx.doi.org/10.4271/2013-26-0095

2 Nunes, A., Martins, E., Guaragna, L., and Mariano, $\mathrm{S}$. A case study about side door closing sound quality, 2008 SAE BRASIL Noise and Vibration Conference, Florianópolis, SC, Brazil, March 30-April 01, (2008). https://dx.doi.org/10.4271/2008-36-0590

3 Parizet E, Guyader E, and Nosulenko V. Analysis of car door closing sound quality, Applied Acoustics, 69, 12-22, (2008). https://dx.doi.org/10.1016/j.apacoust.2006.09.004

4 Shin, T.J., Park, D.C., and Lee, S.K. Objective evaluation of door-closing sound quality based on physiological acoustics, International Journal of Automotive Technology, 14, 133-41, (2013). https://dx.doi.org/10.1007/s12239013-0015-1

5 Hamilton, D. Sound quality of impulsive noises: An applied study of automotive door closing sounds, Noise and Vibration Conference and Exposition, Traverse City, Michigan, USA, May 17-20, (1999). https://dx.doi.org/10.4271/199901-1684

6 Zhang, Z., and Young, S. Low frequency transient CAE analysis for vehicle door closure sound quality, 
Table 4. Evaluation of design change effects on Sharpness.

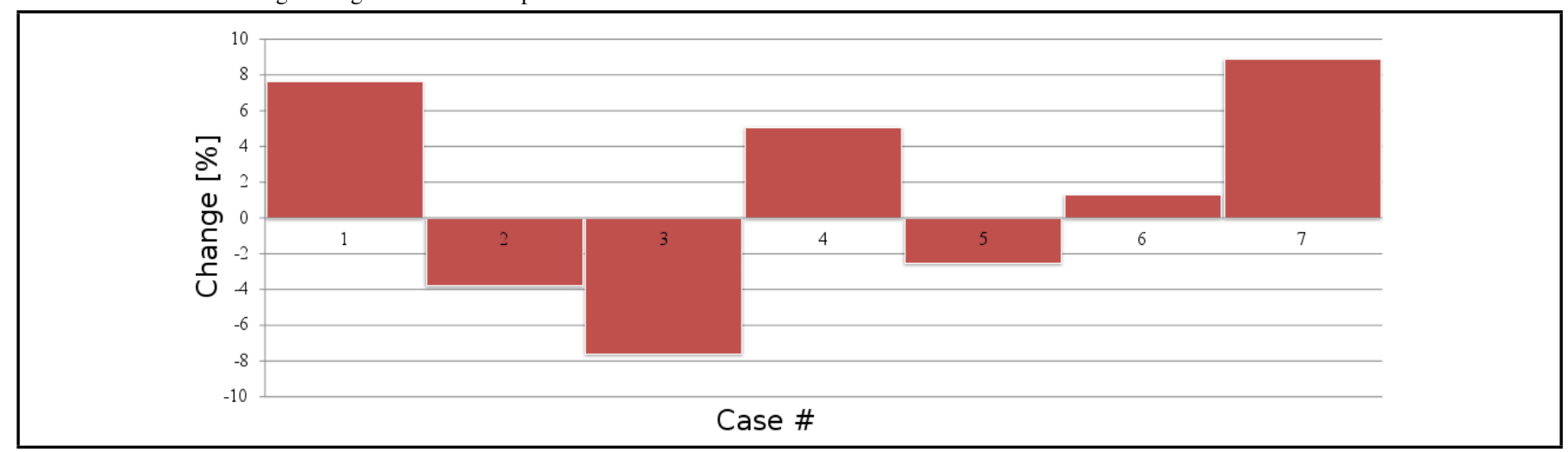

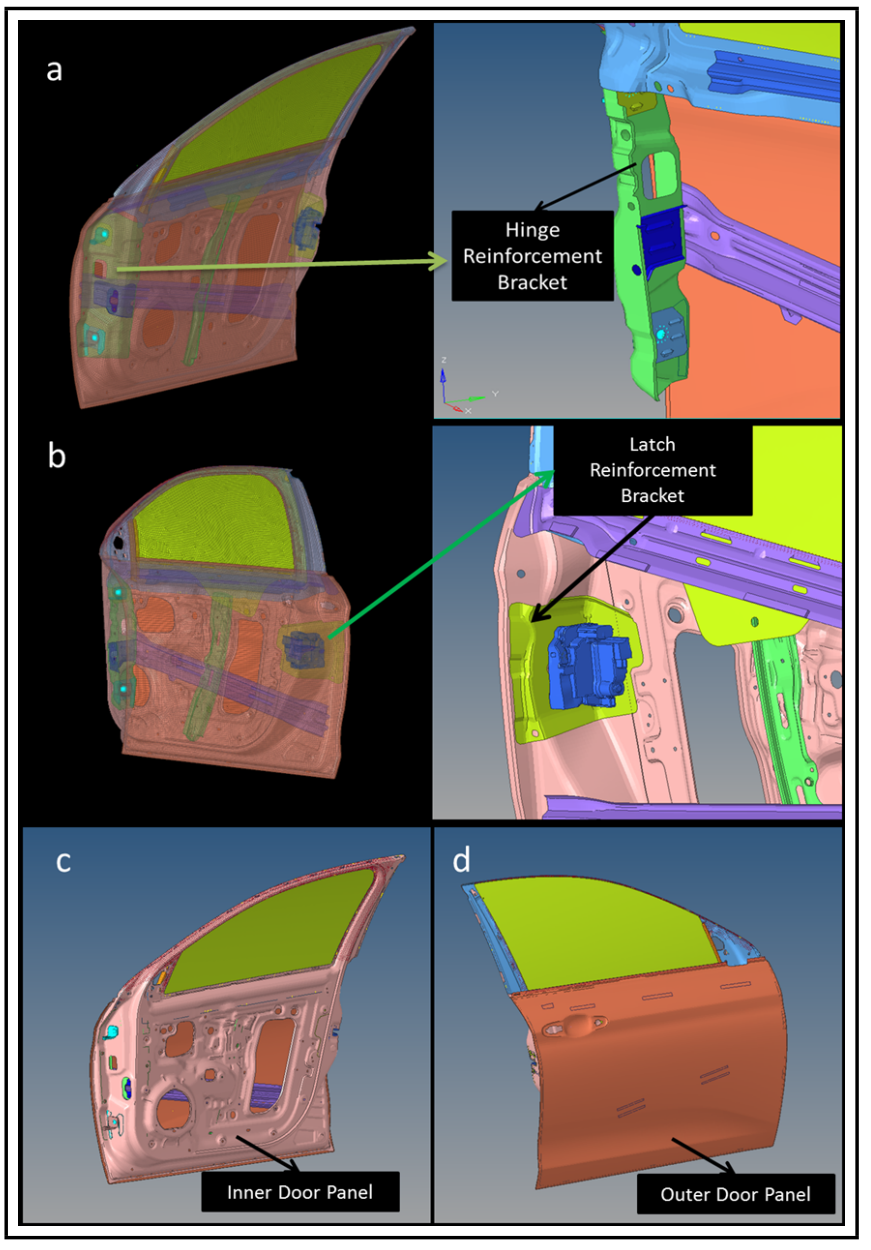

Figure 11. Parts on which design changes were applied: (a) Thickness of Hinge Reinforcement Bracket, (b) Thickness of latch Reinforcement Bracket, (c) Thickness of Inner Door panel, (d) Thickness of Outer Door panel.

SAE 2005 Noise and Vibration Conference and Exhibition, Traverse City, Michigan, USA, May 16-19, (2005). https://dx.doi.org/10.4271/2005-01-2339

$7 \mathrm{Xu}$, Z., Xia, X., Lai, S., and He, Z. Improvement of interior sound quality for passenger car based on optimization of sound pressure distribution in low frequency, Applied Acoustics, 130, 43-51 (2018). https://dx.doi.org/10.1016/j.apacoust.2017.08.019

8 Pereira, F. and de Souza, G. (2010). Automotive door closing efforts study, SAE Technical Paper, 2010-36-0294, (2010). https://dx.doi.org/10.4271/2010-36-0294

9 Ver, I. L., and Beranek, L. L., Noise and Vibration Control
Engineering: Principles and Applications, United States: John Wiley \& Sons, (1992).

10 Öztürk, S., and Erol, H. Numerical and experimental studies on the structure-borne noise control on a residential kitchen hood, International Journal of Acoustics and Vibration, 18 (1), 3-6, (2013). https://dx.doi.org/10.20855/ijav.2013.18.1314

11 Çelikkan, O., and Erol, H. Vibro-acoustic analysis of a refrigerator freezer cabinet coupled with an air duct, $A d$ vances in Acoustics and Vibration, 2017, 1960898, (2017). https://dx.doi.org/10.1155/2017/1960898

12 Gupta, G., Gautam, R., and Jain, C. (2014). Study of coupling behavior of acoustic cavity modes to improve booming noise in passenger vehicles, SAE Technical Paper, 2014-01-1974, (2014). https://dx.doi.org/10.4271/2014-011974

13 Meriç, C., Erol, H. and Özkan, A. Noise contribution analysis of a vehicle passenger compartment, Noise Control Engineering Journal, 64 (5), (2016). https://dx.doi.org/10.3397/1/376409

14 Sung, S., Chao, S., Lingala, H. and Mundy, L. (2011). Structural-Acoustic Analysis of Vehicle Body Panel Participation to Interior Acoustic Boom Noise, SAE Technical Paper, 2011-01-0496, (2011). https://dx.doi.org/10.4271/2011-01-0496

15 Sanderson, M. and Onsay, T. CAE interior cavity model validation using acoustic modal analysis, SAE Technical Paper, 2007-01-2167, (2007). https://dx.doi.org/10.4271/2007-01-2167

16 Meriç, C., Erol, H. and Özkan, A. On the sound absorption performance of a felt sound absorber, Applied Acoustics, 114, 275-280, (2016). https://dx.doi.org/10.1016/j.apacoust.2016.08.003

17 Cook, R. D., Malkus, D. S., Plesha, M. E., and Witt, R. J. Concepts and Applications of Finite Element Analysis, United States: John Wiley \& Sons, (2002).

18 Yang, C., Yu, D., and Xia, B. Research on the sound metric of door-slamming sound based on leaky integration and wavelet decomposition, International Journal of Automotive Technology, 15 (5), 853-860, (2014). https://dx.doi.org/10.1007/s12239-014-0089-4 